\title{
Are Dutch posture verbs lexical or functional elements?
}

\author{
Iris Mulders \\ Utrecht University
}

In Dutch, posture verbs like liggen 'lie' and staan 'stand' are obligatorily used in locative constructions with inanimate subjects, classifying the spatial Figure-Ground relation. Prima facie, in this use, posture verbs seem more like functional elements than like lexical verbs.

This paper investigates processing of Dutch posture verbs in a reference resolution task in the visual world paradigm, to get more clarity on the nature of these verbs. We know that lexical verbs like rinkelen 'ring' cause anticipatory looks towards a matching target referent like telefoon 'telephone'; and that they suppress looks to a phonological competitor like telescoop 'telescope. The functional property of grammatical gender on determiners (de vs. het) is less robust in directing looks. When it comes to anticipating the target referent, and suppressing looks to a phonological competitor, do posture verbs pattern with lexical verbs, or with functional elements like grammatical gender?

Keywords: posture verbs, lexicality, grammatical gender, eye-tracking, visual world paradigm

\section{Are Dutch posture verbs lexical or functional elements?}

Verbs that describe human postures, like stand, sit, and lie, have extended uses in many languages (Newman 2002; Ameka and Levinson 2007). In Dutch, posture verbs are obligatory in locative constructions with inanimate subjects, and their use is further extended to more metaphorical uses (Lemmens 2002), use as progressive-marking auxiliaries (Lemmens 2005; Van Pottelberge 2002), use with complementetive past participles (Bogaards 2019), and quotative use (Bogaards 2020). This paper will focus on the use of posture verbs in locative constructions with inanimate subjects. 
As also remarked by Lemmens (2005), in Dutch, use of a posture verb is practically obligatory in such constructions: (1) using a copula is marked, instead a posture verb has to be used as in (2). ${ }^{1}$

(1) \#De sleutels zijn op tafel

The keys are on table

'The keys are on the table'

(2) De sleutels liggen op tafel

The keys lie on table

'The keys are lying on the table'

Not any posture verb can be used. Dutch uses only four posture verbs with inanimate subjects, namely staan 'stand', zitten 'sit', liggen 'lie', and hangen 'hang' (so, not verbs like hurken 'crouch' or leunen 'lean'); out of these four verbs, a choice has to be made for the correct one:

(3) ${ }^{\star}$ De sleutels staan / zitten / hangen op tafel ${ }^{2}$

The keys stand / sit / hang on table

'The keys are standing/sitting/hanging on the table'

The choice of posture verb is partly determined by the orientation of the subject (4-5), but it is not the posture of the subject alone that determines the choice of posture verb. Rather, these verbs seem to encode the relationship between the Figure and the Ground, as evidenced by the posture verb changing when the Ground changes in (6):

(4) Het boek staat in de kast

The book stands in the bookcase

'The book is in the bookcase (in an upright, vertical orientation)'

(5) Het boek ligt in de kast

The book lies in the bookcase

'The book is in the bookcase (in a horizontal orientation)'

1. It is possible to use a copula in certain contexts, for instance when questioning the location Waar zijn de sleutels? 'Where are the keys?', or when the posture of the object is not known De bezem is op zolder 'The broom is in the attic' (could be standing or lying). For extensive discussion, see Lemmens (2002, pp.132-135).

2. It is possible to think of contexts in which 'ungrammatical' posture verbs do work; for instance, De sleutels staan op tafel would be fine to describe the posture of a number of giant keys (that could be used as advertising material for a shop duplicating keys for instance) if they were stood up on their 'bottom' part or on a stand. 
(6) Het boek zit in de doos

The book sits in the box

'The book is in the box (contained; can be in any orientation)'

It is difficult for non-native speakers to learn which verb to use (Lemmens and Perrez 2012), and actually even native speakers struggle to specify what exactly the posture verbs encode. This is a fascinating question that cannot be addressed in this paper; for some insights into what factors come into play, see Van den Toorn (1975) and Lemmens (2002).

How is this posture verb's encoding of the relationship between the Figure and the Ground established syntactically? This question does not seem to receive much attention in the literature. An intriguing proposal by Hoekstra and Mulder (1990) is that the posture verb takes the locational PP as a small-clause complement, and that the inanimate subject of the posture verb originates in this locational PP, where it gets its theta role before it moves up to the subject position of the posture verb. In this analysis, the posture verb does not select its subject; rather, it selects the locational PP that predicates over the inanimate NP.

Intuitively, these properties of posture verbs in locational constructions with inanimate subjects add up to the impression that they don't seem like 'regular' lexical verbs: perhaps they do not assign a theta role to their subject, they have a difficult-to-pinpoint, fairly abstract meaning, and they are closed-class (only four posture verbs can be used in these constructions). These properties beg the question, are posture verbs, in their use in locational constructions with inanimate subjects, actually more like functional elements than like lexical verbs?

This is the question this paper tries to address, employing a reference resolution task in the visual world paradigm (Cooper 1974; Tanenhaus et al. 1995), in which participants' eye movements in a 'visual world' (depicted on a picture) are monitored while they listen to language related to what they see.

\section{Processing properties of lexical vs. functional elements}

We know from previous research that truly lexical verbs will direct looks in a visual display. For instance, Altmann and Kamide (1999) presented participants with a visual display containing a boy, a toy train, a ball, a toy car and a cake, accompanied by an auditory stimulus The boy will eat the cake or The boy will move the cake. When the verb was eat, looks to the cake went up, even before the word cake had been heard, showing that the selection properties of the verb are used predictively - looks are restricted to the object that can fulfill the verb's selectional restrictions even before the target word is heard. This ability of verbal 
selectional restrictions to predictively direct looks to the target is a robust finding across many languages (Hintz et al. 2017); even two-year-olds show it (Mani and Huettig 2012).

In addition, selectional restrictions on the verb are able to suppress looks to the phonological cohort. Generally, while a word is being heard, the phonological cohort (words starting with the same sounds) will also be activated in the lexicon, and attract looks in the visual world paradigm. Dahan and Tanenhaus (2004) show that selectional restrictions on the verb suppress looks to these phonological competitors while the target word is being heard, when the competitors do not match the selectional restrictions.

Another linguistic phenomenon that will suppress looks to a phonological competitor is grammatical gender marking on a determiner: if the grammatical gender of the competitor does not match the gender marking on the determiner, looks to the phonological competitor are eliminated or reduced. Dahan et al. (2000) showed that in French, when the target phrase is the grammaticalgender-neutral plural les boutons 'the buttons', participants look more to the phonological competitor les bouteilles 'the bottles' than they look to femininemarked la bouteille when the target phrase is the singular, masculine le bouton.

While grammatical gender on French determiners does restrict looks to the phonological cohort, it does not generate anticipatory looks though. The masculine determiner le did not restrict looks to le bouton and a masculine-gendermatched competitor: participants looked just as much to feminine-gender competitors presented in the same visual display.

In sum: selectional restrictions on lexical verbs and grammatical gender marking on determiners both suppress looks to phonological competitors while the target word is being heard, but only lexical verbs trigger predictive looks to objects that match their selectional restrictions. (We will see in Section 7 that under certain circumstances, grammatical gender marking may generate predictive looks as well, but these circumstances do not arise in the experiment reported here).

In this paper, I use this difference between lexical and functional elements as a litmus test to get more understanding about the nature of Dutch posture verbs in their locative use with inanimate subjects: are they lexical or functional elements. 


\section{Eye-tracking experiment comparing posture verbs to lexical verbs and grammatical gender: Method}

\subsection{Participants}

Twenty adult non-dyslectic native speakers of Dutch were recruited from the UiL OTS participant database. They were paid 5 euros for their participation. The experiment was done in the spring of 2010, under implicit informed consent in accordance with Dutch law. The participants' mean age was 21;9, 2 participants were male, 1 left-handed. All had normal hearing and normal vision, or wore contact lenses to correct their vision to normal.

\subsection{Procedure}

Participants were seated in a sound-attenuated booth, where the EyeLink I headmounted eyetracker was fitted to them and calibrated. They received both oral and written instructions about the experiment.

Participants were shown a visual stimulus (for examples see Figures 1 and 5) for $500 \mathrm{~ms}$. This is a short time, enough to not be startled by the audio starting, and to scan part of the visual stimulus. Then a pre-recorded auditory stimulus was presented over speakers, while the visual stimulus stayed on the screen. After the sentence ended, the visual stimulus stayed on the screen for another $750 \mathrm{~ms}$ (enough time to fully finish processing the sentence), before a yes/no label was presented; the participants were asked to answer 'yes' when the answer to the question asked in the auditory stimulus was 'yes' for the accompanying visual stimulus, or 'no' when it was not, by pressing the corresponding button on a button box.

In total, the experiment consisted of 139 trials: 67 fillers (of which 24 had an expected 'no' response), and 72 experimental items ( 12 items in 3 'verb' conditions (see Section 4) plus 12 items in 3 'grammatical gender' conditions (see Section 5), all with an expected 'yes' response). The experimental block was preceded by a practice block consisting of 5 practice items, of which one had an expected 'no' response.

The trials were presented in a different pseudorandomized order for each participant: the same picture never appeared twice in a row, and items in the same condition never appeared consecutively either. 


\section{Comparing posture verbs to lexical verbs}

\subsection{Materials in the 'verb' conditions}

All visual stimuli consisted of a simple landscape or room containing four evenly spaced objects in a somewhat surrealistic arrangement. Figure 1 gives an example.

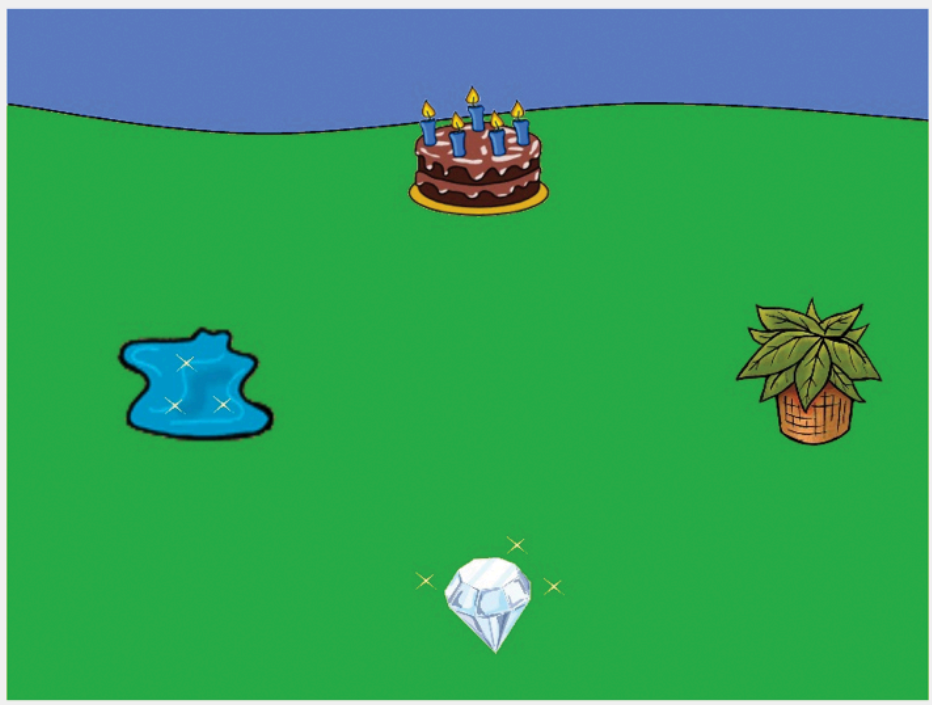

Figure 1. Example of a visual stimulus in the 'verb' conditions

This visual stimulus appeared three times in the stimulus set, accompanied by different auditory stimuli, as in (7):

(7) a. 'see' neutral condition

Zie je een plas in het veld?

See you a puddle in the field?

'Do you see a puddle in the field?'

b. posture verb condition

Ligt er een plas in het veld?

Lies there a puddle in the field?

'Is there a puddle lying in the field?' 


\section{c. lexical verb condition}

Glinstert er een plas in het veld?

Sparkles there a puddle in the field?

'Is there a puddle sparkling in the field?'

The 'lexical verb' condition was named thus to highlight the (potential) difference with the posture verbs in these locative constructions with inanimate subjects. That is not to say that zie 'see' in the neutral condition is not a lexical verb, which of course it is. The difference between zie and the verbs in the 'lexical verb' condition is that zie does not have selectional restrictions that restrict looks to any of the objects in the picture (its only restriction on its object is that it must be visible, which in a picture of course they are), while the verbs in the 'lexical verb' condition do have meaningful selectional restrictions - they are not compatible with all the objects in the picture.

In the 'lexical verb' condition, most of the verbs were theme unergatives. Finding one-place verbs that can be depicted in a static image was not trivial, and, like (8c), most of the sentences we ended up with in the lexical verb condition are somewhat unnatural.

The point of this triplet of conditions is to see whether posture verbs differ from verbs that certainly are truly lexical. As we have seen, the posture verbs in this use potentially are more like functional elements and may not even syntactically select their subject; yet a given posture verb will not be compatible with all objects in a picture like Figure 1, because some of them 'stand' and others 'lie' in the field.

We limited the posture verbs in the posture verb condition to just staan 'stand' and liggen 'lie.' We did not use zitten 'sit', because it is mainly used for containment relations like De bal zit in de doos 'The ball sits in the box', which would require a container that would then itself 'stand' in the room, and that would introduce ambiguity as to what the potential target could be. Some ambiguity cannot be avoided, because, as an anonymous reviewer points out, the objects themselves already have subparts that can all be combined with a posture verb - for instance, the cake in Figure 1 has candles on it that 'stand'(or maybe 'sit') on the cake. In all the stimuli (including fillers), the object that the target word referred to was not a subpart of an object, precisely to avoid confusion about which objects would be potential targets.

3. One anonymous reviewer asks whether participants wouldn't interpret staan in its use as 'be in a picture', in which case staan would trigger looks to all the objects in the picture. To check this, I took a post-hoc look at plots of the AOIs comparing staan to liggen (which cannot be used in this sense). No difference between liggen and staan presented itself. 
We didn't use hangen 'hang' for similar reasons: hangen requires something to hang from (say, a coat rack), which might again form a potential target in participants' minds. Also, while it is a full member of the set staan, liggen, zitten, hangen that is used with inanimate subjects in locative constructions, hangen intuitively seems a bit more marked; it is less frequent than the other posture verbs, and it is acquired later (Mulders and Koring 2020).

\subsection{Predictions for the 'verb' conditions}

\subsubsection{Anticipatory looks to the matched distractor}

We expect the lexical verb to direct looks to the target before the target word has even been heard. To get the clearest possible picture of these predictive looks, without the onset of the target word interfering, a competitor was included in the visual stimulus that matches the target in the sense that it could also be the subject of the lexical verb, or of the posture verb. In the stimulus depicted in Figure 1 above, for instance, plas 'puddle' is the target, it sparkles, and it also 'lies' in the field. Its matched distractor is the diamant, 'diamond', which also sparkles and 'lies' in the field. ${ }^{4}$ The other objects in the picture, the cake and the plant, neither sparkle nor 'lie' (they 'stand').

We expect looks to the matched distractor diamant 'diamond' to start rising when the lexical verb glinstert is heard; when the verb is zie 'see' there is no reason to look at any of the objects over the others so we expect to see no rise in looks to the matched distractor in that condition; and it is an open question whether the posture verb ligt 'lies' behaves like the lexical verb, i.e. directs looks to the matched

4. Two anonymous reviewers bring up the 'movability' of the objects depicted. They point out that the puddle in Figure 1 can only 'lie' - it has no structural integrity whatsoever, so it cannot 'stand', 'sit', or 'hang' - and ask whether this shouldn't have been controlled for, since the other objects in the picture can assume more than one posture, for instance if the plant were tipped to its side, it would be 'lying' rather than 'standing.'

In fact we initially tried to find objects that would combine with only one posture verb, but this turned out to be impossible - so much so that in the end, the puddle in Figure 1 is the only object in the entire stimulus set that can combine with only one posture verb. Pretty much anything in this world can combine with multiple posture verbs. Things that 'lie' can usually also 'hang' (a necklace) or 'sit' inside a container; pretty much anything that 'stands' can be made to 'lie' by being tipped on its side, or by stripping it of its function (for instance a bed usually stands, but on a garbage heap, it would 'lie'; moreover, as pointed out by Van den Toorn (1975), a bed can 'sit' in a moving truck). 
distractor diamant, or whether it behaves like a function word, which we expect to not direct predictive looks to the matched distractor. ${ }^{5}$

\subsubsection{Suppressing looks to the phonological cohort after target word onset}

At the onset of the target word, we expect looks to go up to the target (plas 'puddle'), but also to the object that starts with the same sounds (plant 'plant') when the verb is the neutral zie 'see.' We expect the lexical verb to suppress these looks to some extent, because the phonological competitor does not match the selectional restrictions of the verb (the plant does not sparkle). We expect the posture verb to do the same, since the plant is not 'lying', it is 'standing. If the posture verb is a lexical verb, we expect it to suppress the looks to the cohort as well as the lexical verbs do; if the posture verb is a function word, we also expect it to suppress looks to the cohort, but maybe less so.

\subsection{Response data}

Overall, participants gave the expected 'yes' or 'no' response in $99 \%$ of the cases. Table 1 gives averages of the response data for the fillers, and for the 'verb' conditions. Mixed models (with random intercepts for subjects and items) were fit for whether the answer given was correct, and for the response times in the 'verb' conditions. No significant differences between the conditions were found.

Table 1. Response data in the 'verb' conditions

\begin{tabular}{lccc}
\hline Condition & $\begin{array}{c}\text { Average proportion correct } \\
\text { answers }\end{array}$ & $\begin{array}{c}\text { Average response time } \\
(\mathbf{m s})\end{array}$ & $\begin{array}{c}\text { SD response time } \\
(\mathrm{ms})\end{array}$ \\
\hline Fillers & 0.98 & 421 & 337 \\
$\begin{array}{l}\text { See } \\
(\text { neutral })\end{array}$ & 1.00 & 365 & 208 \\
$\begin{array}{l}\text { Posture } \\
\text { verb }\end{array}$ & 0.98 & 388 & 274 \\
$\begin{array}{l}\text { Lexical } \\
\text { verb }\end{array}$ & 0.97 & 379 & 213 \\
\hline
\end{tabular}

5. As one reviewer and Frank Wijnen (p.c.) point out, the diamond in Figure 1 does not unambiguously 'lie' - it could be perceived as being in an upright position (although it would be hard pressed to 'stand' on its pointy end), or as sort of floating rather than 'lying'. This is a shortcoming of this particular item that is not pervasive in the stimulus set as a whole. 


\subsection{Eye-tracking data preprocessing and analysis}

\subsubsection{Preprocessing}

After visual inspection in the program Fixation (Cozijn 2007), 25 trials were removed before analysis due to tracker loss $(<2 \%$ of the data, 14 trials in the 'verb' conditions, 11 in the 'gender' conditions). The segments for the audio stimuli were coded in Praat (Boersma 2001). I used R (R Core Team 2020), Rstudio (R Studio Team 2020), and eyetrackingR (Dink and Ferguson 2015) for further preprocessing, aggregating the data into $50 \mathrm{~ms}$ time bins.

To determine the time window for the analyses, I looked at the plot for the cohort activation effect in Dahan and Tananhaus (2004) and concluded that the full rise and fall of the curve was from about $200 \mathrm{~ms}$ after target word onset (which is the time it takes to plan and execute a saccade) until about $800 \mathrm{~ms}$ after target word onset. So I used this window to analyze the data from this experiment for the cohort suppression effect.

I used a similar window - $200 \mathrm{~ms}$ until $800 \mathrm{~ms}$ after verb onset - for the analysis of the looks to the matched distractor during the verb. This is also approximately the length of the pre-target auditory segment (6o1 ms on average in the 'verb' conditions, and $522 \mathrm{~ms}$ in the 'gender' conditions).

\subsubsection{Growth curve analysis}

I employed growth curve analysis (GCA, Mirman 2014) to model the evolution of proportions of looks over time. GCA fits curves to the data and statistically assesses the overall slope and bends in these curves. I used third-order orthogonal polynomials with fixed effects for condition on all time terms, including byparticipant random intercepts as well as random slopes for condition and for as many time terms as model convergence would allow; for the model formulas, see appendices A-C. I used lme4 (Bates et al. 2015) and multcomp (Hothorn et al. 2008, version 1.4.16) to establish statistical significance for contrasts between conditions, and stargazer (Hlavac 2018) to format the resulting contrast tables (in appendices $\mathrm{A}-\mathrm{C})$.

\subsection{Eye-tracking results}

To give a general idea of how the visual stimuli were processed, Figure 2 provides a plot of the looks to each of the four areas of interest (AOI) in the 'verb' conditions, starting from verb onset. The $\mathrm{Y}$ axes mark proportions of looks to each AOI; the $\mathrm{X}$ axes give time from verb onset. Vertical reference lines mark average segment onsets (+200 ms to allow for saccade planning and execution) for the verb, the target word, the PP, and sentence offset. 


\section{Looks starting from verb onset in the 'verb' conditions}

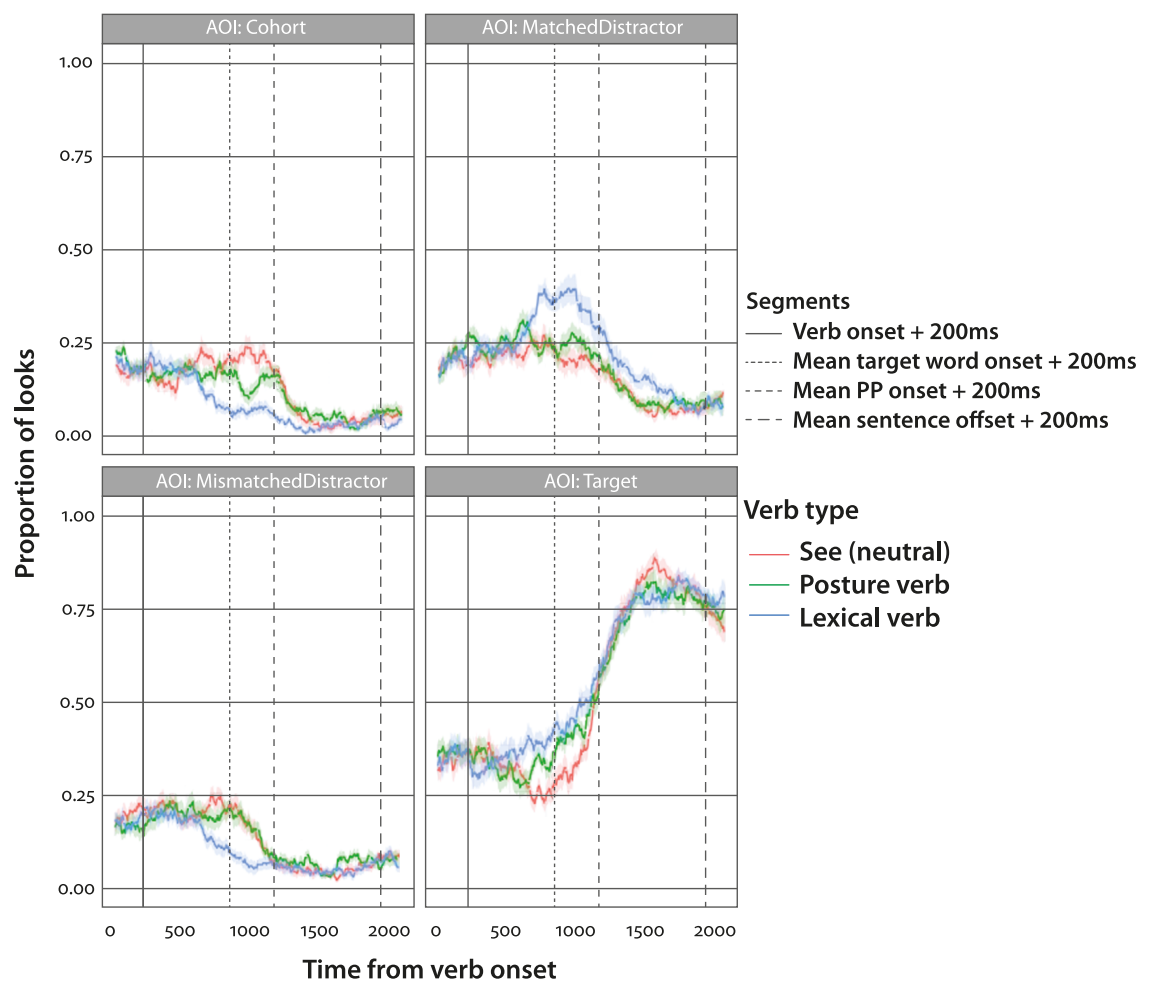

Figure 2. Overall looks in the 'verb' conditions

\subsubsection{Anticipatory looks to the matched distractor}

Appendix A gives the contrasts between the conditions for the looks to the matched distractor during the verb. Figure 3 plots raw data with confidence intervals and model lines.

Contrasts reveal that the slope for the lexical verb condition is significantly steeper than the slope in the neutral condition and the posture verb condition, meaning that the looks to the matched distractor rise more when the verb is a lexical verb than when it is see or a posture verb.

Furthermore, there is a significant difference in the quadratic term for the lexical verb versus the posture verb, indicating that the primary curve is steeper in the posture verb condition, and more shallow in the lexical verb condition. This effect might be interpreted as the posture verbs triggering a more transient rise and fall of looks to the matched distractor, consistent with shorter and lower activation of the matched distractor following the posture verbs than the lexical verbs. Crucially, posture verbs do not differ from 'see' on any of the time terms. 


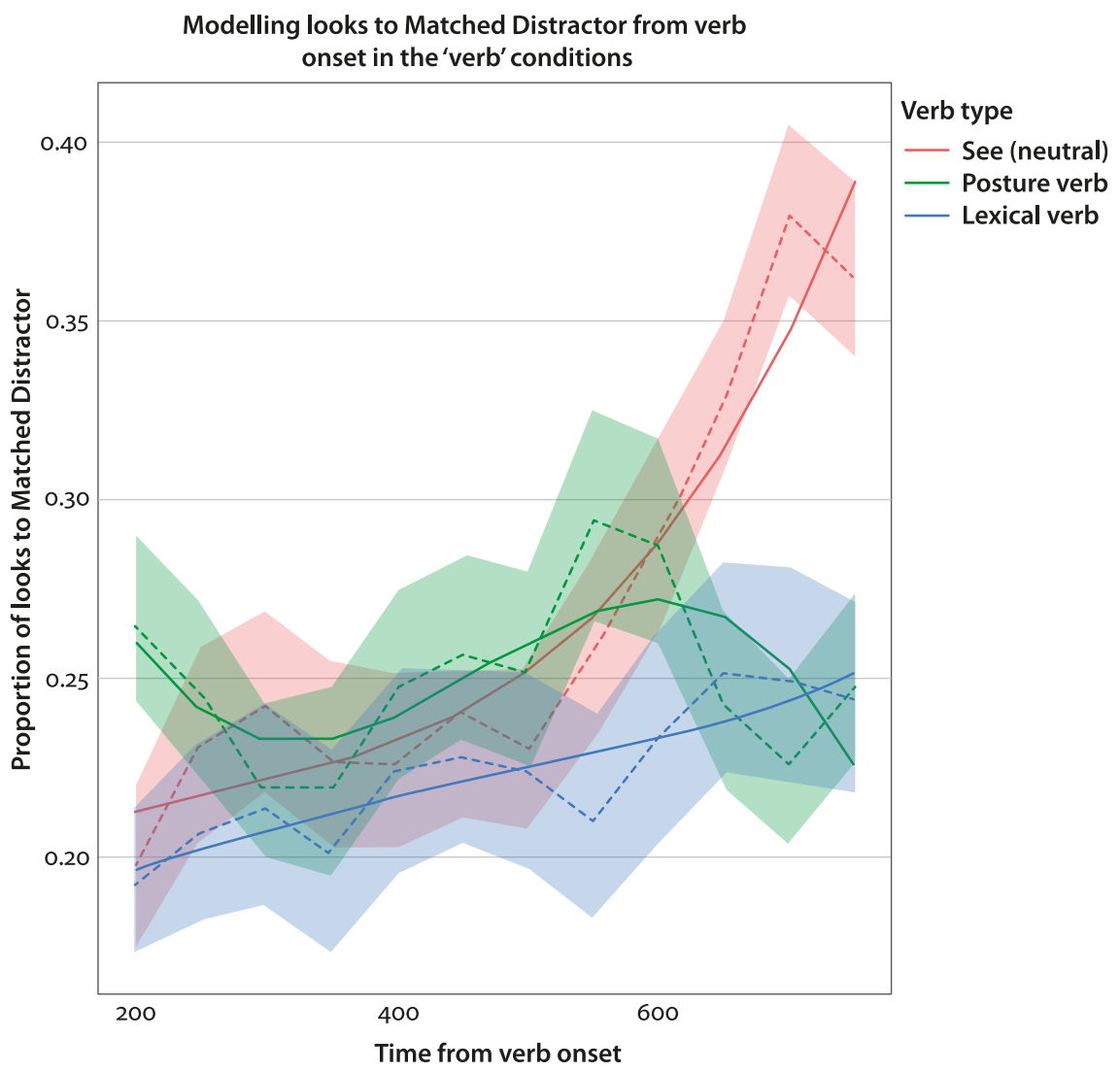

Figure 3. Raw data and model lines for anticipatory looks to the matched distractor in the 'verb' conditions

We can conclude that the lexical verbs trigger anticipatory looks to an object matching their selectional restrictions, as expected; and that posture verbs do not.

\subsubsection{Suppressing looks to the cohort in the 'verb' conditions}

Appendix B gives the contrasts for the looks to the cohort from $200 \mathrm{~ms}$ after target word onset until $600 \mathrm{~ms}$ later. Figure 4 plots raw data and model lines.

Contrasts show that in the lexical verb condition, looks to the cohort in this time window are lower overall than in the other two conditions. Furthermore, contrasts on the linear time term show that the fall in the 'see' condition is significantly steeper than in the other two conditions, and that the fall in the posture verb condition is steeper than in the lexical verb condition. Additionally, the quadratic time term shows significant contrasts between the see condition and 


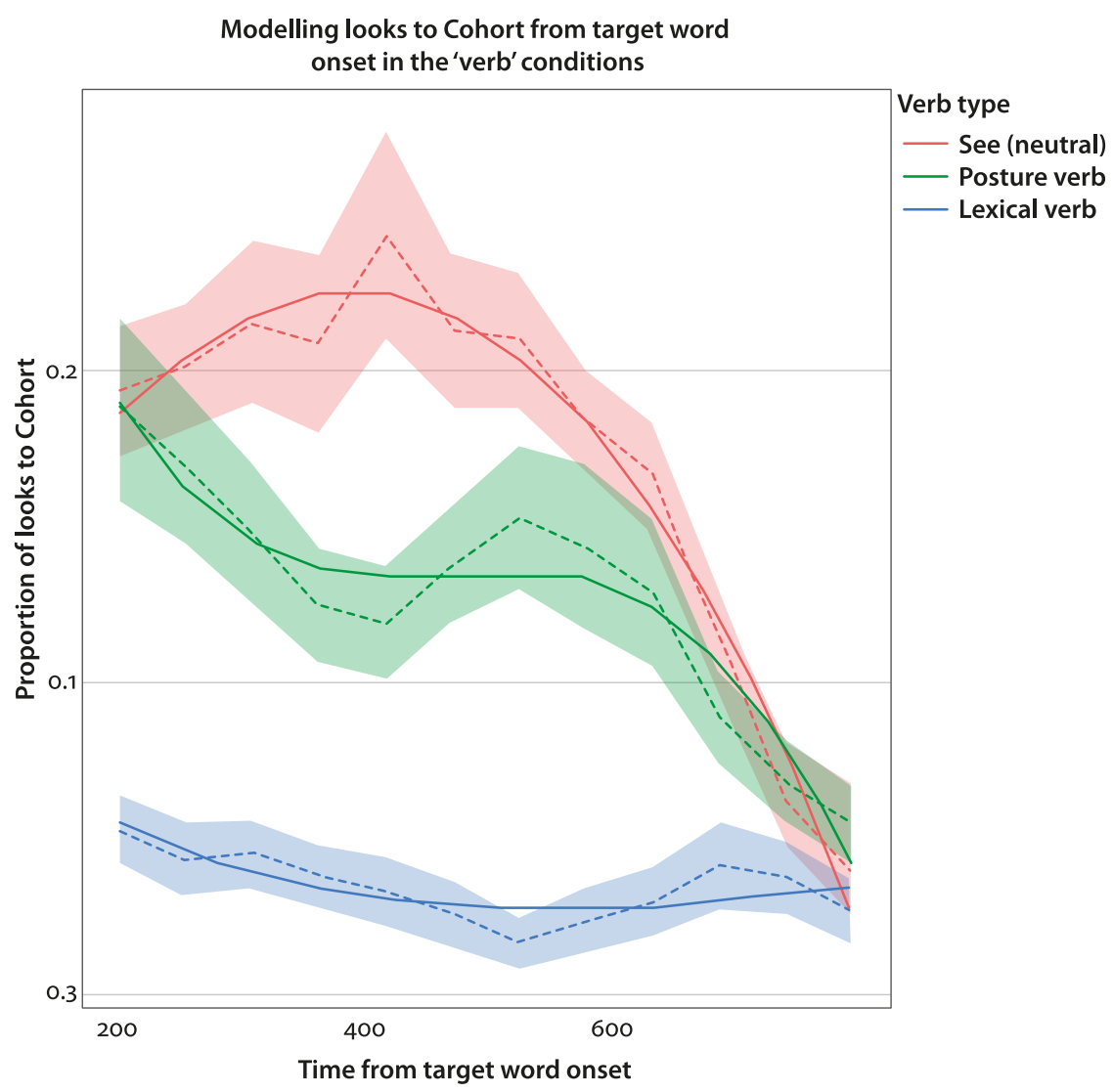

Figure 4. Raw data and model lines for looks to the cohort in the 'verb' conditions

the other two conditions, showing that the looks in the see condition rise before they fall.

These results allow us to conclude that the lexical verb is very successful in suppressing looks to the cohort after target word onset, and that the posture verb suppresses looks to the cohort as well, but not as strongly.

\section{Comparing posture verbs to grammatical gender}

\subsection{Materials in the 'gender' conditions}

The second set of three conditions in this experiment involved grammatical gender; an example visual stimulus is given in Figure 5, and accompanying auditory stimuli in (8). 


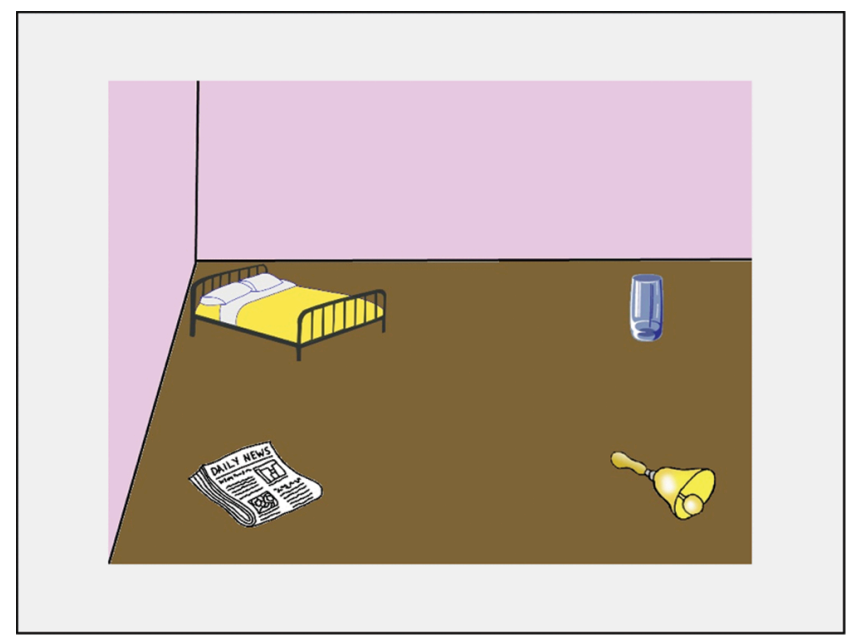

Figure 5. Example stimulus in the 'gender' conditions

(8) a. 'een' neutral condition

Zie je een bed in de kamer?

See you a bed in the room?

'Do you see a bed in the room?'

b. posture verb condition

Staat er een bed in de kamer?

Stands there a bed in the room?

'Is there a bed standing in the room?'

c. 'de/het' grammatical gender condition

Zie je het bed in de kamer?

See you the.Neuter bed in the room?

'Do you see the bed in the room?'

In this example stimulus, bed 'bed' is the target: it goes with the neuter determiner het, and it also 'stands' in the room. Its matched distractor is the glas, 'glass', which also has neuter gender and also 'stands' in the room; the other two objects in the picture, the bell and the newspaper, both have common gender and 'lie'. The bel 'bell' does belong to the phonological cohort for the target bed.

5.2 Predictions for the 'gender' conditions

\subsubsection{Anticipatory looks to the matched distractor}

We do not expect to find predictive looks to the matched distractor in any of the conditions; we already know from the 'verb' conditions that the posture verb does 
not generate predictive looks, and we know from the literature that grammatical gender is not likely to do it either.

\subsubsection{Suppressing looks to the phonological cohort after target word onset}

At the onset of the target word, we expect looks to go up to the target bed, but also to the phonological cohort ( $b e l$ 'bell') when the verb is the neutral zie 'see. We expect grammatical gender to suppress these looks to some extent, because the phonological competitor does not have the same grammatical gender. We expect the posture verb to do the same, since the bell is not 'standing. We already know from the 'verb' conditions that the posture verb does suppress looks to the cohort, the question here is how it compares to grammatical gender - does it do as well as grammatical gender, or maybe even better?

\subsection{Response data}

Table 2 provides averages for the response data in the 'gender' conditions. There were no significant differences between the 'gender' conditions for response time or correctness of the answers.

Table 2. Response data in the 'gender' conditions

\begin{tabular}{lccc}
\hline Condition & $\begin{array}{c}\text { Average proportion correct } \\
\text { answers }\end{array}$ & $\begin{array}{c}\text { Average response } \\
\text { time }(\mathrm{ms})\end{array}$ & $\begin{array}{c}\text { SD response } \\
\text { time (ms) }\end{array}$ \\
\hline $\begin{array}{l}\text { een (no grammatical } \\
\text { gender) }\end{array}$ & 1.00 & 369 & 199 \\
$\begin{array}{l}\text { Posture verb } \\
\text { de/het (grammatical } \\
\text { gender) }\end{array}$ & 1.00 & 399 & 288 \\
\hline
\end{tabular}

5.4 Eye-tracking data analysis

The analysis for the 'gender' conditions was identical to the analysis for the 'verb' conditions.

\subsection{Results}

To give an idea of how participants processed the visual stimuli in the 'gender' conditions overall, looks to the four areas of interest are plotted in Figure 6. 
Looks starting from verb onset in the 'gender' conditions

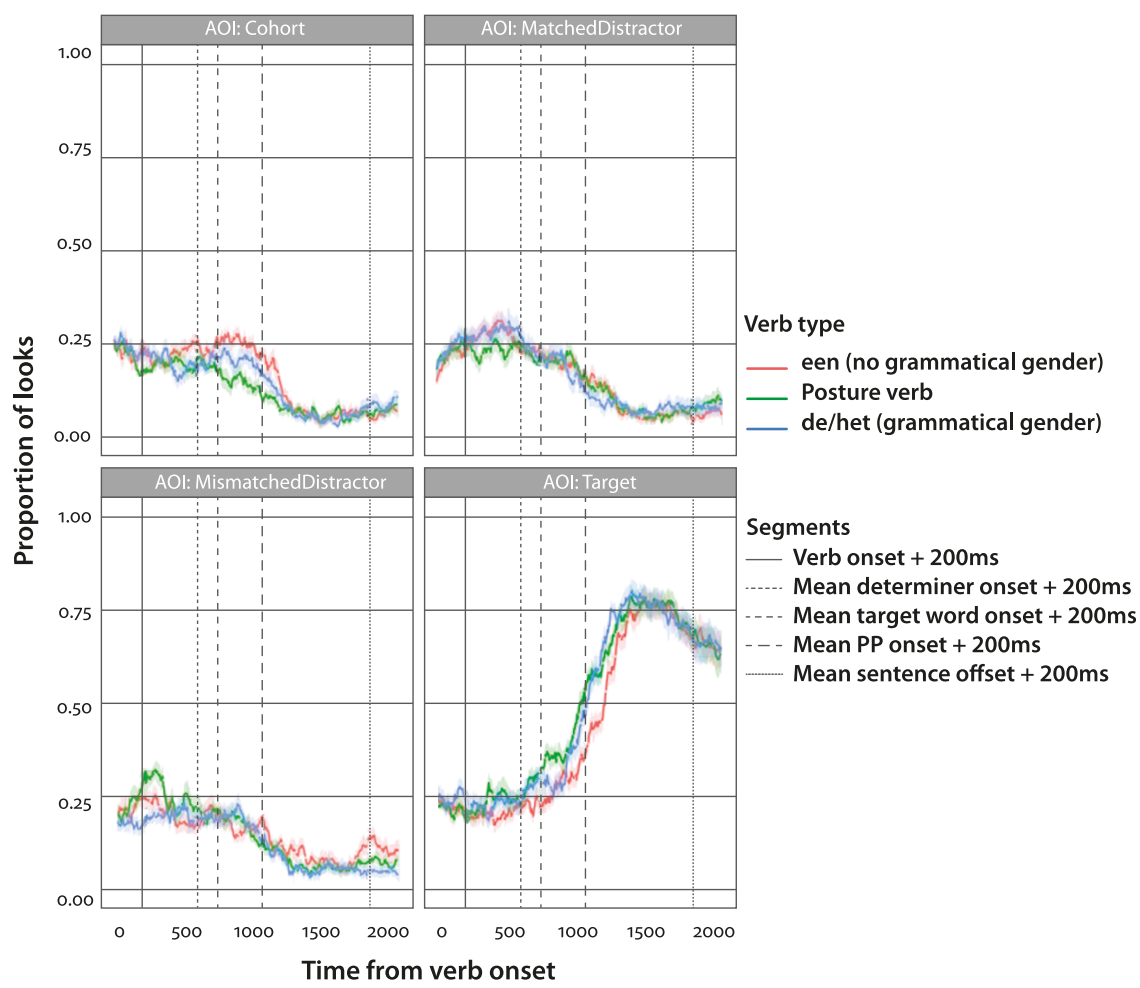

Figure 6. Overall looks in the 'gender' conditions

\subsubsection{Anticipatory looks to the matched distractor}

The time window from $200-800 \mathrm{~ms}$ after verb onset showed no significant differences between conditions on any of the time terms. This is in line with our expectations, and replicates the finding from the 'verb' conditions that posture verbs do not trigger anticipatory looks.

\subsubsection{Suppressing looks to the cohort in the 'gender' conditions}

Appendix $\mathrm{C}$ provides a table with the contrasts between the conditions for the looks to the cohort from $200 \mathrm{~ms}$ after target word onset until $600 \mathrm{~ms}$ later. Figure 7 plots raw data and model lines.

Contrasts show that overall in this time window, there are more looks to the cohort in the neutral baseline condition than in the posture verb condition. The looks in the posture verb fall significantly less steeply than in the other two conditions. The quadratic term indicates that the line for the posture verb condition 


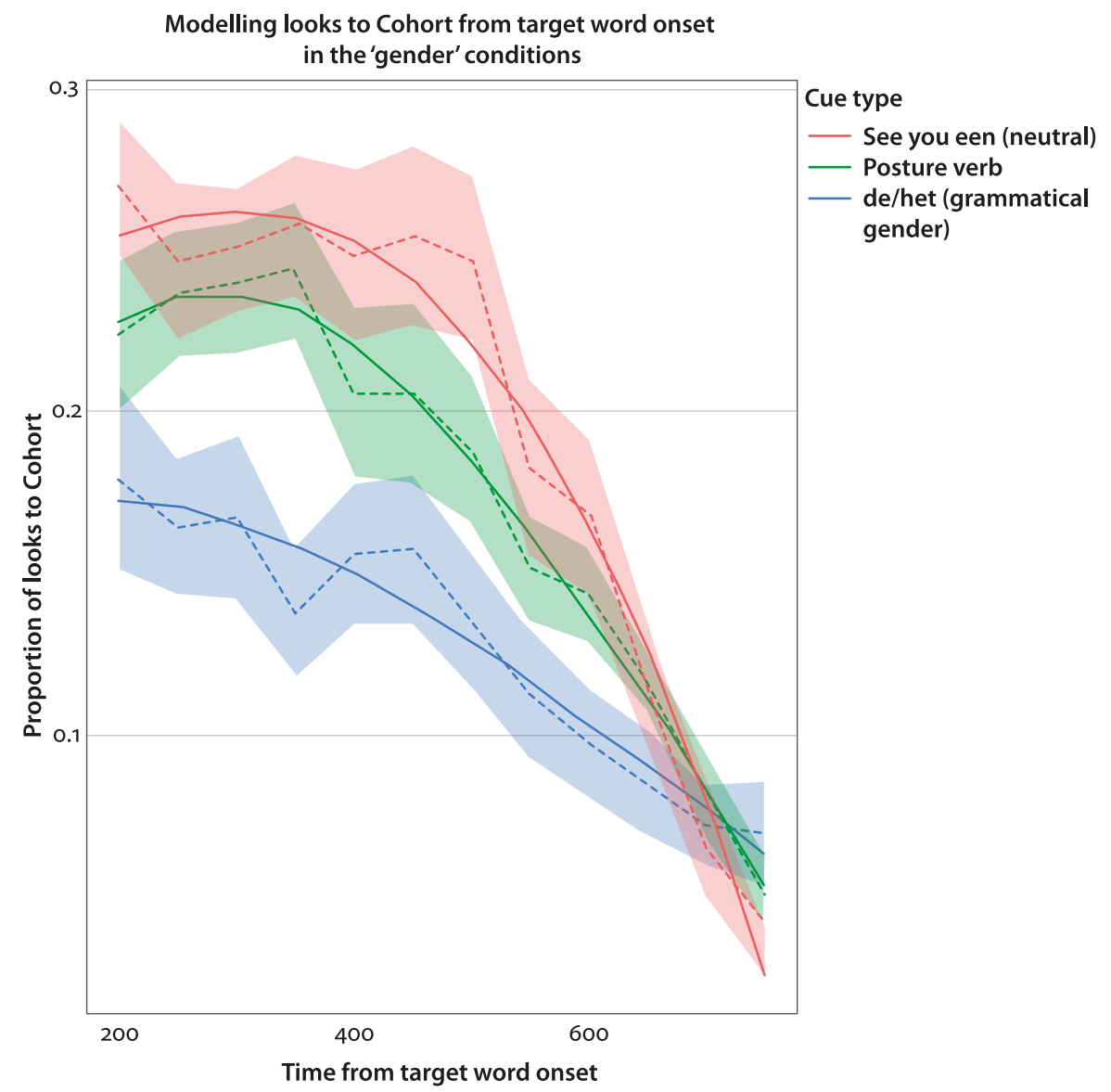

Figure 7. Raw data and model lines for looks to the cohort in the 'gender' conditions

has a flatter shape than the line for the neutral verb. There are no significant differences between the neutral and the gender-marked condition.

All in all, these results are consistent with the conclusion that the posture verb suppresses looks to the cohort rather effectively. Contrary to expectation, we did not find any evidence that gender marking on the determiner suppresses looks to the cohort as well; therefore we cannot conclude that the posture verb behaves like a functional element here, as it outperforms the functional element in this experiment. 


\section{Discussion}

The picture that emerges is that posture verbs are 'in between' lexical and functional elements: they do not trigger anticipatory looks like lexical verbs do, but they are better than grammatical-gender marking on determiners at suppressing looks to a phonological competitor. Before we jump to the conclusion that posture verbs must then be semi-lexical in nature, let us consider some alternative explanations.

\subsection{Could it be frequency?}

Frequency and condition are very closely correlated in this experiment: by far the most frequent elements are the determiners, then follow the posture verbs, and the lexical verbs are the least frequent potentially looks-directing words (ignoring the verb zie 'see' in the neutral conditions because zie does not have selectional restrictions that would direct looks in the context of this experiment). The high frequency of determiners and posture verbs implies that they are not very distinctive, they can combine with a lot of things, and maybe this could explain why they do not direct looks as much as selectional restrictions on lexical verbs do: as cues, they are simply not distinctive enough in general (even though they are in the context of this experiment).

To see if this thought holds any merit, I did a post-hoc analysis of the looks to the matched distractor for only the lexical verbs in the $200-800 \mathrm{~ms}$ following the verb, using third-order orthogonal polynomials, with a fixed effect for centered log-frequency (obtained from SUBTLEX-NL, Keuleers et al. 2010) on all time terms, including by-item random intercepts as well as random slopes for the linear and quadratic time terms. I used lmerTest (Kuznetsova et al. 2017) to obtain p-values. Appendix D provides the formula and fixed-effects table. Figure 8 plots the model lines and raw data.

There is a significant interaction between verb frequency and the cubic time term, showing that the less frequent verbs show a stronger second bend and a later peak, which means that looks go up later for the less frequent verbs. In other words, the high-frequency verbs are better at directing looks. This runs counter to the idea that high-frequency words like posture verbs and grammatical gender would be bad at directing looks because they are high-frequency - within the class of lexical verbs, we see the opposite happening.

This is a very interesting result if true, but there is reason to be cautious. Puzzlingly, frequency also has a (small) significant effect on the intercept, i.e. on the looks at the start of the time window; this can not have been caused by the verbs' frequencies, since it takes about $200 \mathrm{~ms}$ to plan and execute a saccade. The 


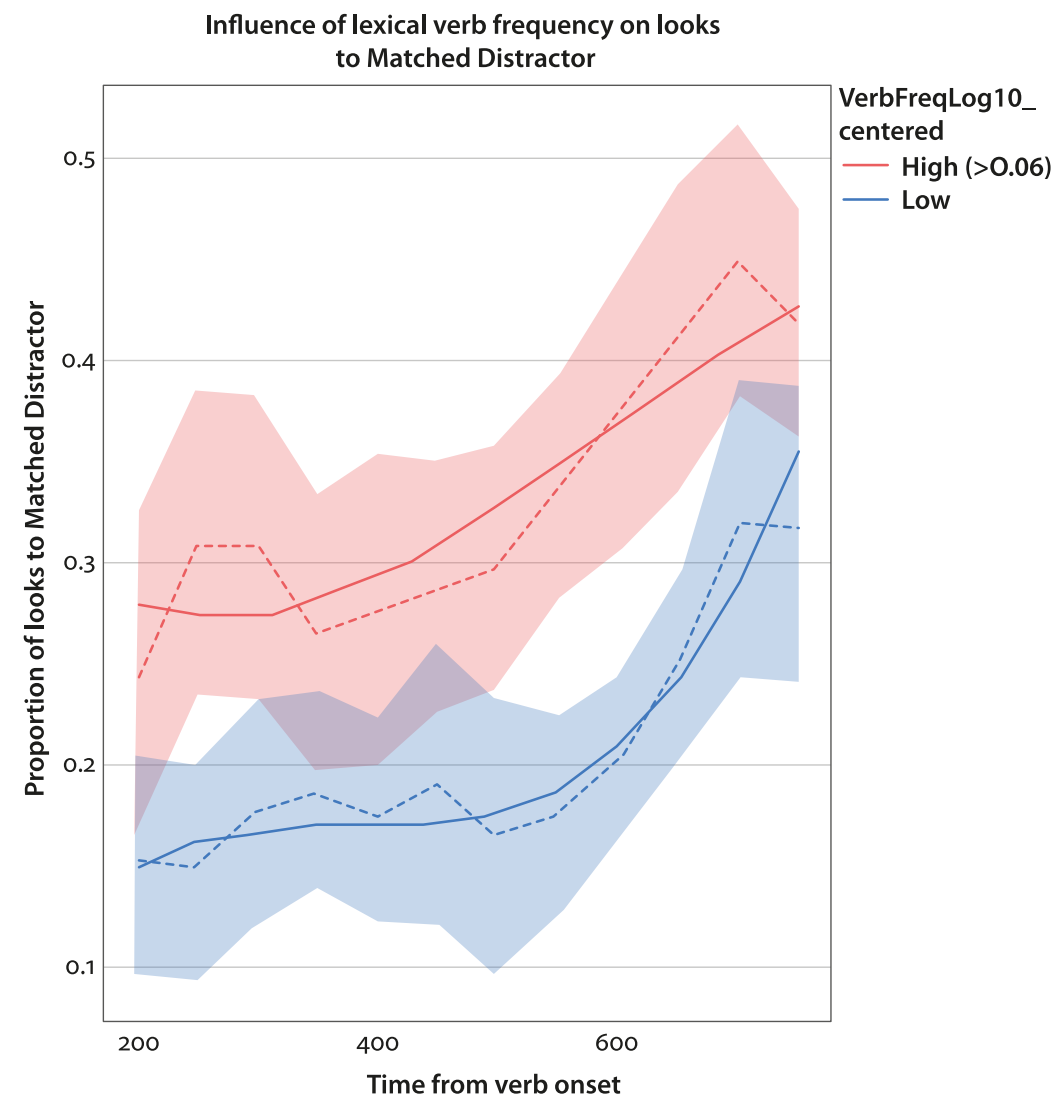

Figure 8. The influence of lexical-verb frequency (plotted as median split for expository purposes) on looks to the matched distractor

effect might be due to a potential confound in the pictures - a post-hoc inspection of the pictures reveals that the items with the lower-frequency verbs have the matched distractor in the bottom half of the picture more often than the higherfrequency verb items. (Note that this potential confound only arises because we are doing a post-hoc comparison here between items, rather than conditions in the between-condition comparisons we did so far, the matched distractor is always in the same position in all three conditions because the same picture is presented).

This frequency effect does seem interesting enough to warrant future research; but future experiments should carefully control for the location of the areas of interest. It may also be wise to allow participants more time to scan the picture before the sentence starts - the $500 \mathrm{~ms}$ used in this experiment is too short a time to properly see all four objects. 


\subsection{Could it be the pictures?}

The observant reader will have noticed in Figure 1 that the diamond and the puddle had starry bits in/around them, to make it clear that they sparkle. In 9 out of 12 items in the 'verb' conditions, the picture had 'something' to make it match the sentence in the lexical verb condition - for instance a jukebox and a radio were embellished with musical notes to show they were 'playing. One might suspect that this would make it easier for participants to identify the objects matching the verbs' selectional restrictions, compared to how easy it is to identify the objects' posture (although intuitions about standing vs. lying in the items are very clear, visually most of the objects are rather 'blob'-like - it is not horizontal vs. vertical orientation that discerns most of them).

It seems unlikely that this potential difference in 'findability' was responsible for the predictive looks in the lexical-verb condition, though. All three items that did not have 'something' to make the target and matched distractor successful matches for the selectional restrictions of the verb, were in the top-five verbs with the highest frequency; and we have just seen that the items employing more frequent verbs were better at generating anticipatory looks to the matched distractor.

\subsection{Could it be time?}

Time-wise, the posture verb and grammatical gender do not line up in the 'gender' conditions; the posture verb necessarily appears well before the target word, while the determiner appears directly before it, and is, on average, only $140 \mathrm{~ms}$ long. This could be why the posture verbs are more successful in suppressing looks to the cohort: there has simply been more time to let their restrictions sink in.

After the experiment in this paper had been conducted, some experimental findings were published that support this line of thought. Brouwer et al. (2017) show that Dutch adults can actually use grammatical gender predictively, given enough time, i.e. when there is an adjective separating the determiner and the target noun. Evidence for grammatical gender generating predictive looks in Dutch is conflicted though - Brouwer et al. find it only for neuter gender, while Loerts et al. (2013), who also employ adjectives to give more time, find only a facilitative (no predictive) effect of grammatical gender, and only for common gender. 


\section{Conclusion}

We can tentatively conclude that posture verbs are unlike regular lexical verbs; whether they are truly functional elements or semi-lexical, still remains to be convincingly determined.

\section{Funding}

Open Access publication of this article was funded through a Transformative Agreement with Utrecht University.

\section{Data archive}

All stimuli, data and analysis scripts can be found at https://doi.org/10.24416/UUo1-KIL8QR.

\section{Acknowledgments}

Many thanks to Mari Chanturidze, Marjolein van Egmond, Ileana Grama, Suzanne Hermans, Julia Mitlina, and Aikaterini Pantoula (students in the Eye-tracking research seminar course, 2010), for creating and coding stimuli, keeping logbooks, running participants, and eyemovement data cleanup; to Theo Veenker for programming the experiment; to the audience at the Grote Taaldag 2020; and to Loes Koring, Eric Reuland, Norbert Cover, Joost Zwarts, and Kriszta Szendrői for boosting my courage to finally get this data set out of my drawer and into the world.

\section{References}

Altmann, G. \& Y. Kamide. 1999. "Incremental interpretation at verbs: restricting the domain of subsequent reference." Cognition 73(3): 247-264. https://doi.org/10.1016/So010-0277(99)00059-1

Ameka, F. K. \& S. C. Levinson. 2007. "Introduction: the typology and semantics of locative predicates, posturals, positionals and other beasts." Linguistics 45: 847-871. https://doi.org/10.1515/LING.2007.025

Bates, D., M. Maechler, B. Bolker \& S. Walker. 2015. "Fitting Linear Mixed-Effects Models Using lme4." Journal of Statistical Software, 67(1): 1-48. https://doi.org/10.18637/jss.vo67.io1 Boersma, P. 2001. "Praat, a system for doing phonetics by computer." Glot International 5(9): 341-345. 
Bogaards, M. 2019. "Sitting stuck and standing scribbled: Productivity, structure, and meaning of posture verbs combined with a complementive past participle in Dutch.” MA thesis, Leiden University, https://www.maartenbogaards.nl/papers/2019/bogaards_2019 _mathesis.pdf

Bogaards, M. 2020. "Gezichten, gedachten en gesprekken: Quotatieven in het Nederlands van nu." Neerlandistiek: Online tijdschrift voor taal- en letterkunde, https://neerlandistiek.nl /2020/o2/gezichten-gedachten-en-gesprekken/

Brouwer, S., S. Sprenger \& S. Unsworth. 2017. "Processing grammatical gender in Dutch: Evidence from eye movements." Journal of Experimental Child Psychology 159: 50-65, https://doi.org/10.1016/j.jecp.2017.01.007

Cooper, R. M. 1974. "The control of eye fixation by the meaning of spoken language." Cognitive Psychology 6: 84-107. https://doi.org/10.1016/0010-0285(74)90005-X

Cozijn, R. 2007. Fixation 0.1.0.15, software for clean-up and coding of EyeLink data.

Dahan, D., D. Swingley, M. Tanenhaus \& J. Magnuson. 200o. "Linguistic Gender and SpokenWord Recognition in French." Journal of Memory and Language 42: 465-480. https://doi.org/10.1006/jmla.1999.2688

Dahan, D. \& M. Tanenhaus. 2004. "Continuous mapping from sound to meaning in spokenlanguage comprehension: immediate effects of verb-based thematic constraints." Journal of Experimental Psychology: Learning, Memory, and Cognition 30(2): 498.

Dink, J.W. \& B. Ferguson. 2015. eyetrackingR: An R Library for Eye-tracking Data Analysis. Retrieved from http://www.eyetrackingr.com

Hintz, F., A.S. Meyer \& F. Huettig. 2017. "Predictors of verb-mediated anticipatory eye movements in the visual world." Journal of Experimental Psychology: Learning, Memory, and Cognition, 43(9): 1352.

Hlavac, M. 2018. stargazer: Well-Formatted Regression and Summary Statistics Tables. R package version 5.2.1.

Hoekstra, T. \& R. Mulder. 1990. "Unergatives as copular verbs; locational and existential predication.” The linguistic review 7: 1-79. https://doi.org/10.1515/tlir.1990.7.1.1

Hothorn, T., F. Bretz \& P. Westfall. 2008. "Simultaneous Inference in General Parametric Models." Biometrical Journal 50(3): 346-363. https://doi.org/10.1002/bimj.200810425

Keuleers, E., M. Brysbaert \& B. New. 2010. "SUBTLEX-NL: A new frequency measure for Dutch words based on film subtitles." Behavior Research Methods 42(3): 643-650. https://doi.org/10.3758/BRM.42.3.643

Kuznetsova, A., P. B. Brockhoff \& R. H. B. Christensen. 2017. "ImerTest Package: Tests in Linear Mixed Effects Models." Journal of Statistical Software, 82(13): 1-26, https://doi.org/10.18637/jss.vo82.i13

Lemmens, M. 2002. “The semantic network of Dutch posture verbs." Typological Studies in Language 51: 103-140. https://doi.org/10.1075/tsl.51.07lem

Lemmens, M. 2005. “Aspectual posture verb constructions in Dutch." Journal of Germanic linguistics 17(3): 183-217. https://doi.org/10.1017/S1470542705000073

Lemmens, M. \& J. Perrez. 2012. "A quantitative analysis of the use of posture verbs by Frenchspeaking learners of Dutch." CogniTextes. Revue de l'Association française de linguistique cognitive 8. https://doi.org/10.4000/cognitextes.609

Loerts, H., M. Wieling \& M.S. Schmid. 2013. "Neuter is not common in Dutch: Eye movements reveal asymmetrical gender processing." Journal of psycholinguistic research 42(6): 551-570. https://doi.org/10.1007/s10936-012-9234-2 
Mani, N. \& F. Huettig. 2012. "Prediction during language processing is a piece of cake - But only for skilled producers." Journal of Experimental Psychology: Human Perception and Performance 38(4): 843 .

Mirman, D. 2014. Growth Curve Analysis and Visualization Using R. Boca Raton, FL: Chapman and Hall/CRC Press.

Mulders, I. \& L. Koring. 2020. "The many ways to stand, lie and sit" (paper presented at the Grote Taaldag, 31 January, Utrecht).

Newman, J., ed. 2002. The linguistics of sitting, standing and lying (Vol. 51). John Benjamins Publishing. https://doi.org/10.1075/tsl.51

$\mathrm{R}$ Core Team. 2020. $R$ : A language and environment for statistical computing. R Foundation for Statistical Computing, Vienna, Austria, https://www.R-project.org/

RStudio Team. 2020. RStudio: Integrated Development Environment for R. RStudio, PBC, Boston, MA, http://www.rstudio.com/

Tanenhaus, M., M. Spivey-Knowlton, K. Eberhard \& J. Sedivy. 1995. "Integration of visual and linguistic information during spoken language comprehension." Science 268: 1632-1634, https://doi.org/10.1126/science.7777863

Toorn, M.C. van den. 1975. "Over de semantische kenmerken van staan, liggen en zitten." De Nieuwe Taalgids 68: 459-464.

Van Pottelberge, J. 2002. "Nederlandse progressiefconstructies met werkwoorden van lichaamshouding: Specificiteit en geschiedenis." Nederlandse Taalkunde 7: 142-174.

\section{Appendix A. Contrasts for the 'verb' conditions during the verb}

Formula: Prop $\sim(\text { ot } 1+\text { ot } 2+\text { ot } 3)^{\star} \operatorname{cond}+(($ ot $1+$ ot 2$)+$ cond $\mid$ subjectnr $)$

\begin{tabular}{lccccc}
\hline & Estimate & Std. Error & z value & $\operatorname{Pr}(>|z|)$ \\
\hline Overall: See vs. Lexical verb & 0.044 & 0.030 & 1.501 & 0.746 \\
Overall: See vs. Posture verb & 0.027 & 0.029 & 0.956 & 0.975 \\
Overall: Lexical verb vs. Posture verb & -0.017 & 0.023 & -0.728 & 0.996 \\
Slope: See vs. Lexical verb & 0.118 & 0.023 & 5.066 & $<0.00001$ \\
Slope: See vs. Posture verb & -0.045 & 0.023 & -1.940 & 0.420 & $* *$ \\
Slope: Lexical verb vs. Posture verb & -0.163 & 0.023 & -7.006 & $<0.00001$ \\
Quadr: See vs. Lexical verb & 0.065 & 0.023 & 2.804 & 0.055 &. \\
Quadr: See vs. Posture verb & -0.015 & 0.023 & -0.662 & 0.998 & \\
Quadr: Lexical verb vs. Posture verb & -0.081 & 0.023 & -3.466 & 0.006 & $* *$ \\
Cubic: See vs. Lexical verb & 0.013 & 0.023 & 0.554 & 0.999 & \\
Cubic: See vs. Posture verb & -0.053 & 0.023 & -2.262 & 0.223 & \\
Cubic: Lexical verb vs. Posture verb & -0.066 & 0.023 & -2.816 & 0.053 &. \\
\hline
\end{tabular}

(Adjusted p values reported - single-step method) 


\section{Appendix B. Contrasts for the 'verb' conditions during the target word}

Formula: Prop $\sim(\text { ot } 1+\text { ot } 2+\text { ot } 3)^{*} \operatorname{cond}+(($ ot 1$)+$ cond $\mid$ subjectnr $)$

\begin{tabular}{lcccc}
\hline & Estimate & Std. Error & $\mathrm{z}$ value & $\operatorname{Pr}(>|\mathrm{z}|)$ \\
\hline Overall: See vs. Lexical verb & -0.136 & 0.016 & -8.624 & $<0.00001^{* * *}$ \\
Overall: See vs. Posture verb & -0.044 & 0.023 & -1.902 & 0.437 \\
Overall: Lexical verb vs. Posture verb & 0.092 & 0.013 & 6.973 & $<0.00001^{* * *}$ \\
Slope: See vs. Lexical verb & 0.151 & 0.019 & 8.035 & $<0.00001^{* * *}$ \\
Slope: See vs. Posture verb & 0.058 & 0.019 & 3.099 & $0.021^{*}$ \\
Slope: Lexical verb vs. Posture verb & -0.093 & 0.019 & -4.936 & $0.00001^{* * *}$ \\
Quadr: See vs. Lexical verb & 0.147 & 0.019 & 7.826 & $<0.00001^{* * *}$ \\
Quadr: See vs. Posture verb & 0.104 & 0.019 & 5.525 & $<0.0000 x^{* * *}$ \\
Quadr: Lexical verb vs. Posture verb & -0.043 & 0.019 & -2.301 & 0.199 \\
Cubic: See vs. Lexical verb & 0.0001 & 0.019 & 0.005 & 1 \\
Cubic: See vs. Posture verb & -0.045 & 0.019 & -2.373 & $0.168^{*}$ \\
Cubic: Lexical verb vs. Posture verb & -0.045 & 0.019 & -2.378 & 0.166 \\
\hline
\end{tabular}

\section{Appendix C. Contrasts for the 'gender' conditions during the target word}

Formula : Prop $\sim\left(\text { ot } 1_{1}+\mathrm{ot}_{2}+\mathrm{ot}_{3}\right)^{\star}$ ordered_cond $+\left(\left(\right.\right.$ ot $\left._{1}+\mathrm{ot}_{2}+\mathrm{ot}_{3}\right)+$ ordered_cond $\mid$ subjectnr $)$

\begin{tabular}{lccccc}
\hline & Estimate & Std. Error & z value & $\operatorname{Pr}(>|z|)$ \\
\hline Overall: Neutral vs. Gender & -0.022 & 0.020 & -1.064 & 0.954 \\
Overall: Neutral vs. Posture verb & -0.067 & 0.017 & -3.960 & 0.001 & $\star \star *$ \\
Overall: Gender vs. Posture verb & -0.046 & 0.019 & -2.462 & 0.139 \\
Slope: Neutral vs. Gender & 0.038 & 0.022 & 1.710 & 0.593 \\
Slope: Neutral vs. Posture verb & 0.116 & 0.022 & 5.251 & $<0.00001$ & $\star * *$ \\
Slope: Gender vs. Posture verb & 0.078 & 0.022 & 3.541 & 0.005 & $\star *$ \\
Quadr Neutral vs. Gender & 0.043 & 0.022 & 1.954 & 0.410 & \\
Quadr: Neutral vs. Posture verb & 0.090 & 0.022 & 4.055 & 0.001 & $\star * *$ \\
Quadr: Gender vs. Posture verb & 0.046 & 0.022 & 2.101 & 0.313 & \\
Cubic: Neutral vs. Gender & 0.020 & 0.022 & 0.924 & 0.980 & \\
Cubic: Neutral vs. Posture verb & 0.013 & 0.022 & 0.577 & 0.999 & \\
Cubic: Gender vs. Posture verb & -0.008 & 0.022 & -0.347 & 1.000 & \\
\hline
\end{tabular}




\section{Appendix D. Frequency effects}

Formula: Prop $\sim\left(\text { ot } 1+o t 2+o t 3_{3}\right)^{\star}$ VerbFreqLog10_centered $+(($ ot1 1 ot 2$) \mid$ item $)$

\begin{tabular}{lcccccc}
\hline & Estimate & Std. Error & df & t value & $\operatorname{Pr}(>|\mathbf{t}|)$ & \\
\hline Intercept) & 0.268 & 0.034 & 12.000 & 7.792 & $<0.00001$ & $* * *$ \\
ot1 & 0.178 & 0.040 & 12.000 & 4.395 & 0.0009 & $* * *$ \\
ot2 & 0.071 & 0.030 & 12.000 & 2.371 & 0.035 & $*$ \\
ot3 & 0.017 & 0.016 & 108.000 & 1.032 & 0.304 & \\
VerbFreqLog10_centered & 0.088 & 0.040 & 12.000 & 2.196 & 0.049 & $*$ \\
ot1:VerbFreqLog10_centered & 0.001 & 0.047 & 12.000 & 0.021 & 0.983 & \\
ot2:VerbFreqLog10_centered & -0.037 & 0.035 & 12.000 & -1.068 & 0.306 & \\
ot3:VerbFreqLog10_centered & -0.049 & 0.019 & 108.000 & -2.549 & 0.012 & $*$ \\
\hline
\end{tabular}

\section{Address for correspondence}

Iris Mulders

Utrecht institute of Linguistics OTS

Utrecht University

Janskerkhof 13

3512 BL Utrecht

The Netherlands

i.c.m.c.mulders@uu.nl

\section{Publication history}

Date received: 15 April 2021

Date accepted: 15 June 2021 